Artigo

ENCARTE DIGITAL

\title{
Orfandade por violência doméstica contra a mulher \\ Uma pesquisa biográfica
}

\section{Orphanage through domestic violence against women A biographical research}

Kamila Almeida*

\begin{abstract}
Resumo: Este artigo apresenta o tema da violência doméstica contra a mulher por um ângulo pouco usual nas Ciências Sociais. As brigas e ameaças que ocorrem no lar, muitas vezes, têm os filhos como plateia. Com o assassinato da mãe pelo pai ou padrasto, inicia-se uma segunda fase do problema, perpetuada pelos órfãos. Por meio da abordagem metodológica de narrativas biográficas foi possível conhecer elementos do mundo da vida de um órfão e compreender de que maneira ele vivenciou a morte da mãe em um contexto violento. Observou-se que, apesar de marcante, a orfandade não é o tema central desta apresentação biográfica. O fio condutor desta trajetória é o fato de ter crescido em abrigo "sem pai nem mãe". É amparado nesta realidade que o entrevistado busca recursos para sobreviver e para se livrar do estigma.
\end{abstract}

Palavras-chave: Violência doméstica contra a mulher. Orfandade. Narrativas biográficas.

\begin{abstract}
This research presents a discussion about domestic violence against woman by an unusual angle at Social Sciences. The fights and intimidation that happen at home, often are witnessed by the children. When a woman, that is mother, is murdered by her partner starts the second phase of problem, that continuous with the orphans. Through the methodological approach biographical narratives it was possible to know elements of a orphan's life-world and understand how he experienced his mother's death in a context of domestic violence. Despite the importance in the interviewee's life, the death of his mother is not the main episode of his telling biography. The connecting thread of his trajectory is the fact that he grew up in an orphan asylum, without father and mother. This situation is what makes Joaquim try to find resources to survive and get rid of the stigma.
\end{abstract}

Keywords: Domestic violence against woman. Orphanage. Biographical narrative.

\footnotetext{
* Mestre em Ciências Sociais (Pucrs, Porto Alegre, Brasil), doutoranda do PPG em Ciências Sociais da Pucrs, Porto Alegre, Brasil<Kamila2708@yahoo.com.br>.
} 


\section{Introdução}

A violência doméstica remete a uma relação de poder onde há intimidação e subordinação do outro, usualmente silenciada e que assume um caráter de abuso, seja ele físico ou psicológico (Sousa, 2013, p. 29). As agressões ocorridas no âmbito doméstico não afetam apenas o casal. A bibliografia sobre o assunto aponta que, muitas vezes, a violência contra mulher tem implicações sobre os filhos. Milani (2006) indica uma lacuna na literatura brasileira ao abordar apenas os efeitos da violência direta contra a criança e não as consequências para os filhos da violência de pais ou padrastos contra a mãe.

Os estudos sobre o tema costumam apenas explicar e descrever o fenômeno, buscando caracterizar casos registrados em órgãos de proteção, além de uma análise histórica, psicológica e moral envolvendo o problema (Milani, 2006). No Brasil, estas investigações se originam na década de 1980, período em que foram criados os primeiros espaços para combater especificamente a violência contra a mulher (Pinto, 2003). Naquela época, o principal objetivo era dar visibilidade à problemática e combatê-la por meio de intervenções psicológicas, jurídicas e sociais destinadas à mulher (Santos e Izumino, 2005).

Uma vasta literatura tem sido produzida nas últimas décadas acerca da violência doméstica contra a mulher e também a praticada contra a criança nas mais variadas disciplinas e com as mais distintas ênfases. Entretanto, ao cruzar os termos violência doméstica contra a mulher ou feminicídio e orfandade, não foram encontrados trabalhos que dêem conta deste assunto na sociologia brasileira.

A orfandade foi debatida, mesmo que de forma escassa, em diversos âmbitos, principalmente na área de saúde pública. Andrea Paula Ferrara (2009) focou a orfandade em decorrência da Aids, buscando compreender o significado de ser órfão para jovens que perderam um ou ambos os pais e compreender os processos de estigmatização decorrentes dessa morte. Ela encontrou cinco significados associados à orfandade: "dificuldade de falar sobre a orfandade ligada à Aids; sentir falta do cuidado materno; o desafio de ser independente; não se sentir órfão e sentir tristeza em decorrência da morte" (Ferrara, 2009, p. 81).

Na psicologia social, Moratilla-Olvera e Taracena-Ruiz (2012, p. 843), afirmam que entre os problemas inerentes às crianças e adolescentes órfãs está a carência de modelos adultos, com uma íntima relação afetiva, em que se espelhar.

Foi por acreditar que muito do que as pessoas que passaram pela experiência de ter a mãe assassinada por violência doméstica têm a dizer está 
nas entrelinhas que busquei na abordagem metodológica de Gabriele Rosenthal, de narrativas biográficas, ferramentas para desvendar o mundo da vida de um órfão. Com isso, a intenção é começar a traçar um entendimento sobre o tema e apresentar uma das tantas formas de vivenciar a orfandade em um contexto violento como este.

Apresento a reconstrução da vida vivenciada de Joaquim, que ficou órfão de mãe aos cinco anos em um contexto de violência doméstica. Assim como ele, Ricardo, o irmão dois anos mais novo, viveram na casa de uma tia, que não teria tido condições financeiras e psicológicas para cuidar dos dois e os encaminhou para um abrigo. Cresceram em uma instituição que possuía um padrão de classe média, em contraste com o nível socioeconômico experimentado junto aos familiares.

Foi por intermédio de um dos abrigos por onde os irmãos passaram que conheci Joaquim. O contato com ele se deu com a ajuda de uma das técnicas que trabalhava, à época, na instituição. O acesso a Ricardo me foi negado por Joaquim e, segundo relatos da funcionária em questão, o irmão estava internado na Fundação de Atendimento Sócio-Educativo do Rio Grande do Sul (Fase/RS), informação posteriormente confirmada com o órgão.

A reconstrução biográfica que será apresentada aqui é fruto de um trabalho de mais de um ano desde a realização de duas entrevistas com Joaquim ${ }^{2}$, cada uma com cerca de 2 horas de conversa, cuja transcrição resultou em 84 páginas, até a análise do material. Foram seguidos os passos da análise recomendados por Rosenthal (2014b), onde são exploradas hipóteses sobre as opções que estariam disponíveis ao entrevistado ao longo do seu percurso desde o seu nascimento até o momento da entrevista, além das escolhas realmente feitas por ele.

Estas hipóteses seguem o princípio de abdução desenvolvido por Charles Sanders Peirce, onde todo o processo de análise dos dados consiste na formulação de hipóteses cuja confecção surja a partir do caso empírico. Elas são formuladas, verificadas, reexaminadas, refutadas ou ampliadas tendo a entrevista narrativa como base (Rosenthal, 2014a).

\footnotetext{
${ }^{1}$ Para Schutz, o conhecimento do indivíduo que age e pensa no mundo da vida cotidiana é incoerente, parcialmente claro e não totalmente livre de contradições. Cada indivíduo constrói seu mundo particular. A fabricação deste universo único é feita com auxílio dos materiais e métodos oferecidos por terceiros. O mundo da vida, portanto, já vem pré-estruturado para o indivíduo (Schutz, 2003; 2012). A interpretação do mundo da vida é baseada no estoque de experiências com que se teve contato durante a socialização (Dreher, 2011).

2 A fim de preservar a identidade do biografado, o nome dele, de todos os familiares, além de bairros, estabelecimentos comerciais ou instituições que possam identificá-lo foram alterados.
} 
As conclusões apresentadas podem parecer dizer respeito exclusivamente à trajetória de Joaquim. Porém, segundo Rosenthal (2014b), generalizar não significa apenas encontrar uma frequência de casos semelhantes. Isto porque, a base da abordagem metodológica interpretativa está na dialética entre o "individual" e o "geral", juntamente com a ideia de que o "geral está, por princípio, implicado no particular" (Rosenthal, 2014b, p. 90).

Ao reconstruir o caso biográfico, o pesquisador explora aspectos da vida do entrevistado, os manifestos e os latentes, e compara as ações dele com o que há disponível na literatura. Rosenthal explica que este tipo de reconstrução esclarece o caso em particular, ou seja, a trajetória do biografado em que há uma implicância mútua entre biografia individual e a história social - realidade subjetiva e realidade coletiva. A autora sinaliza que "biografia, em seu processo concreto de desenvolvimento, mas também quando reexaminada pelo entrevistado a partir do momento presente, é sempre dual, produto ao mesmo tempo individual e coletivo" (Rosenthal, 2014b, p. 224).

\section{A vida de Joaquim}

Joaquim, pardo, cabelos negros enrolados rente à cabeça, nasceu em 1994 na periferia de Porto Alegre, cresceu em abrigo e ficou órfão de mãe quando tinha cinco anos. Ele é o primeiro dos três filhos de Maria - que o teve aos 17 anos - todos de pais diferentes. Joaquim pouco sabe da história da mãe, não conheceu os avós nem o pai. Sobre este último, ouviu dizer que se tratava de um homem de origem germânica. A mãe era negra. Da família, tem contato apenas com três tias da parte materna, seus respectivos maridos e filhos.

Durante a entrevista, Joaquim parece dividir a vida em duas fases. A primeira, do nascimento até os cinco anos. A segunda, da orfandade, aos cinco anos, em diante. Raras são as informações a respeito da primeira fase. Nem lembranças nem histórias que tenha ouvido sobre o seu nascimento. Altair, o padrasto, é a única referência masculina que o biografado apresenta na primeira fase de sua infância. Ele é pai da irmã caçula, Beatriz. A vida para Joaquim parece, pela entrevista, começar apenas na segunda fase. Recorda apenas de assistir, junto do irmão, às repetidas surras que a mãe levava de Altair. Ao aprofundar a narrativa sobre estas lembranças, o jovem descreve a seguinte cena:

lembro dentro de casa eu e meu irmão chorando na cama por causa que ele tinha judiado dela entendeu, mas nós era muito pequeno que nós não podia fazê fazê a nossa dife- " não podia fazê diferen- nós ia fazê o Que: pequeno, dois piá, ele é um homi. ${ }^{3}$

\footnotetext{
${ }^{3}$ N. Ed.: Sobre a técnica de transcrição das entrevistas usada aqui, ver Rosenthal (2014b, p. 113).
} 
$\mathrm{O}$ argumento do biografado é de que, apesar de homem e filho mais velho, tinha apenas cinco anos - idade insuficiente para qualquer atitude contra o padrasto. Saffioti (2001) explica que a violência doméstica e intrafamiliar geralmente ocorre na frente de parentes, principalmente dos filhos -, os integrantes mais fracos desta cadeia.

É possível justificar a culpa velada de Joaquim por não ter contribuído para que as agressões do padrasto sobre a mãe dele se estancassem. Conforme Welzer-Lang (2001) faz parte da socialização masculina a ideia de se manter afastado do estereótipo feminino, sob pena de ser assimilado ou tratado como tal. Porém, Fonseca (2004) mostra que dentre os elementos que compõem a honra masculina estariam o ato de proteger, este sim, sendo sinônimo de virilidade e possível de ser perseguido por alguns homens.

Crianças e jovens são objetos indiretos destas brigas e, segundo Sousa (2013), ao conviver com estas agressões, o mundo destas crianças pode tornarse confuso, assustador e pouco seguro. A autora indica a possibilidade de que iniciem um processo de aprendizado da violência a partir daí, podendo reproduzir este modelo na vida adulta, além de manifestar um intenso sofrimento emocional. Com o tempo, estes sentimentos deletérios são capazes de fazer com que os filhos se julguem responsáveis pelas brigas e também pela resolução dos conflitos dos pais. Nesta atitude de defesa da mãe, muitas vezes os filhos acabam também sendo agredidos (Sousa, 2013).

Saffioti (1999) argumenta que, apesar de a mulher ser o alvo principal na violência doméstica, os filhos também podem ser atingidos. Por serem inferiores na hierarquia, é comum que a mãe os maltrate "ou por síndrome do pequeno poder ou por delegação do macho, acaba exercendo, não raro, a tirania contra crianças, último elo da cadeia de assimetrias" (Saffioti, 1999, p. 84).

A biografia analisada, entretanto, desconstrói esta visão fatalista da reprodução da violência. Em pelo menos três pontos da entrevista, Joaquim frisa um discurso de que não se bate em mulher. Em um deles, diz que se prontificou a defender uma das tias, caso o marido tornasse a surrá-la. Mesmo trazendo relatos de algumas brigas nas quais se envolveu, a violência parece ter mais uma característica de defesa do que de ataque.

\section{Morte da mãe e incertezas}

Era uma manhã chuvosa de 1999. Joaquim foi acordado por um alvoroço. Um vizinho apareceu correndo para ajudar Altair, o padrasto, a acomodar Maria na carroça. Outros queriam saber o que estava acontecendo. Ao fundo, alguém disse: "ela está indo para o hospital ganhar nenê". Da porta de casa, 
Joaquim viu a mãe desaparecer ao longe. Estava deitada ao lado de Altair que dava os comandos ao cavalo. Uma lona preta protegia ambos da tempestade. Joaquim chorava ao ver os dois se afastarem. Um parente tentava acalmá-lo dizendo que logo ela voltaria. Maria tinha 22 anos e estava grávida de Beatriz, filha de Altair. Esta foi a última cena da mãe emoldurada na lembrança de Joaquim. Ela morreu no hospital. A irmã Beatriz se salvou.

Se foi assim que aconteceu, não importa. Interessa aqui saber que é deste jeito que Joaquim se recorda da despedida da sua mãe. O que aconteceu naquele dia, antes do parto, não se sabe, mas as sucessivas agressões de Altair contra Maria foram a causa do falecimento, segundo informações do abrigo. No relato de Joaquim, fica claro que os vizinhos desconfiavam que Maria havia sido morta por Altair e o próprio Joaquim deixa transparecer nas entrelinhas, que há uma dúvida sobre se esta foi ou não a causa da morte. De toda a forma, como não tivemos acesso a boletins de ocorrência ou qualquer laudo que aponte a causa da morte de Maria, nem o discurso de Joaquim é claro o suficiente quanto a isto, a natureza do óbito da mãe do biografado fica em aberto.

A culpa do padrasto fica em suspenso na narrativa de Joaquim. A versão que procura sustentar é a de que a mãe morreu no parto. Foi esta a explicação dada a ele por parentes. Assumir que o padrasto matou a mãe poderia trazer dores ainda mais profundas e exigir dele atitudes que não gostaria de tomar, como uma possível vingança do padrasto. Sobre isto, Joaquim diz:

ai depois que agora eu cresci e eu: eu o meu padrasto que: no tempo batia na minha mãe tá Vivo entendeu, tá vivo, já conversei com ele, já veio do meu lado e fa-veio fala que gostava de mim tudo mais, eu tive a oportunidade de bate nele mi- dez mil vezes, ou até fazê coisa pior com ele quem sabe esquartejar ele todinho por te: por ter batido na minha mãe né meu, por causa que não se bate em mulhe né, pô batê em mulhe é um dos maior crime que tem né meu, /tisc (barulho com a boca)/ mas não eu pensei bem assim, conversei "bastante com meus parente assim", não vale a pena minha tia falou na minha cabeça não vale, "não vale a pena se estressa com ele”.

Para escapar de qualquer compromisso com o verdadeiro ocorrido naquela manhã de 1999, esconde-se na frase: "eu não posso afirmar o que aconteceu. Isso foi o que os meus parentes me contaram". É possível que os familiares tenham omitido os detalhes da morte, justamente por serem os irmãos muito pequenos. Joaquim também, ao que indica em sua narrativa, não fez questão de perguntar à família nem tentar esclarecer. Tomou os relatos deles como verdade. 
Na segunda fase da entrevista, questiono o que Joaquim lembra da última vez que viu a mãe. Ele começa a narrar e, duas frases depois, para. Fricciona as mãos contra os joelhos, parece confuso e assustado com a pergunta. Diz que nunca ninguém havia perguntado isto a ele, o que reforça a hipótese de que o assunto é um tabu ou, no mínimo, desconfortável, para ele. Ele mesmo diz: "eu guardo tudo isto em uma caixinha. Está arquivado na minha memória". É somente na terceira fase de perguntas que Joaquim fornece maiores informações:

ele é foi um covarde na verdade né, ela tava grávida, agrediu minha mãe quando ela tava grávida, na verdade isso ai não se faz entendeu e também só o fato dele encosta um dedo na minha mãe e ele já fez errado entendeu, sabendo que ele que ela que ela tem dois filho e eu acho que ele não penso na situação desses dois filho dela ia cresce entendeu.

Joaquim conta que presenciava várias agressões, mas não fica claro se ele viu a última surra. A hipótese mais provável, sustentada pela afirmação de que Altair é um covarde que batia na mãe dele, mesmo grávida, é a de que tenha presenciado as agressões que a levaram à morte, principalmente, pelo que expõe no relato abaixo:

Bah, eles me disseram que foi no parto né, mas eu sei eu sei que um pouco o meu padrasto judiava um pouco dela, "naque-naquela época quando ela tava grávida eu vi com $=o s=$ meus $=$ próprios $=$ olhos entendeu".

José Carlos Rodrigues (1983) relata como é o entendimento da morte para a criança em diversas fases da vida. Com base nos trabalhos de Piaget sobre o psiquismo infantil, Rodrigues enumera: até os três ou quatro anos a criança não faz ideia do significado da morte como uma separação eterna, ainda que palavras ligadas à morte possam ser percebidas como algo negativo. Nesta fase, pensa que os mortos podem reviver e não carrega a mesma carga emocional característica dos adultos nestas situações. É por volta dos seis anos que toma consciência, afetiva e intelectualmente, mais nítida do significado da morte: teme que a mãe morra, mas se recusa a crer que ela a abandonará um dia. Disso, só começa a estar ciente depois dos sete anos. Aos oito ou nove, sabe que as pessoas morrem depois que alguém as mata ou por motivo de doença e admite que todos morrerão um dia, inclusive ela própria (Rodrigues, 1983, p. 22-23). As afirmações de Rodrigues podem servir para reforçar a hipótese de que Joaquim, que teve a mãe morta aos cinco anos - período em 
que ainda não tomou total consciência do que a morte representa -, realmente pouco tenha aprofundado a questão em conversas com seus familiares e instrutores dos abrigos. Ganha sustentação a hipótese de que o assunto tenha sido deixado de lado e tratado como um tabu e, por isto, menos falado perto das crianças sob um argumento bastante usado quando envolve os pequenos: "eles ainda não entendem".

Ter se tornado um tabu, pode ser uma das razões pelas quais Joaquim sinta dificuldades em verbalizar o que ocorreu com a mãe. A versão de que Maria morreu ao dar à luz Beatriz pode ser mesmo a mais concreta para o biografado e também o jeito mais fácil encontrado pelos tios de explicar para duas crianças pequenas, como era o caso de Joaquim e o irmão dele, Ricardo, o falecimento materno.

Na cultura brasileira, sempre se procurará saber a causa da morte para que o sobrevivente faça uma catalogação quase que automática ligada a uma reação emocional típica de cada um dos tipos de morte, segundo apontou Rodrigues (1983). O autor enumera que uma pessoa pode morrer de "morte morrida", morrer "de velhice", de "morte matada", de "morte violenta" e, cada um destes tipos vai provocar no interlocutor uma reação emocional diversa. Na "morte morrida", que seria a "morte natural", não se faz necessário buscar um culpado. Significa que a existência chegou ao fim e os motivos são relacionados ao funcionamento biológico de cada indivíduo. A morte por velhice seria um bom exemplo deste tipo. A "morte matada" está em um outro extremo e inclui todos os tipos de morte "para os quais se poderia achar um responsável: morte por acidente, assassinato, suicídio" (Rodrigues, 1983, p. 26).

Nesta mesma direção, acrescenta Leis (2003), a morte está inserida em uma zona obscura e mal resolvida da sociedade moderna, onde uma das possibilidades de enfrentá-la está em evitar todo o pensamento que estiver interligado a ela, oprimindo e ocultando a sua presença. O autor acrescenta que, ao se observar em cartórios as causas das mortes em certidões de óbito, ficará constatado que ninguém morre de velho, que a sociedade se recusa a aceitar a chamada "morte natural", obrigando a colocar em todos os casos uma morte bem específica e determinada (Leis, 2003, p. 343-344). Ele salienta uma profunda rejeição dos adultos em falar da morte com seus filhos ou de permitir que tenham contato com a morte de familiares, a fim de evitar que eles se aproximem de algo que possa lhes fazer algum "mal". Pereira (2013) sugere que o luto é vivido de forma pouco expressiva e discreta e que tudo parece, nos dias atuais, empurrar a morte para os "bastidores da vida social". Como lembra Rodrigues, a morte "quebra o curso normal das coisas, questiona 
as bases morais da sociedade e ameaça a coesão e solidariedade do grupo envolvido" (Rodrigues, 1983, p. 93).

É na hora da morte de um membro desta rede de relacionamentos que o sistema se desorganiza e coloca em xeque o comportamento dos que ficam. Um cenário de várias possibilidades de reação diante dos filhos estava disponível aos parentes quando Maria morreu. Os tios poderiam ter se unido para criar os meninos, mas a opção foi colocá-los em um abrigo. Esta manobra terá efeitos diretos sobre a forma como Joaquim vivenciou a orfandade. Não haveria, portanto, como deixar de aprofundar a morte como um tabu nesta biografia específica. Se o óbito é um tabu, inclusive, quando ocorre por doença, que dirá quando o assunto é morte violenta. Rodrigues lembra que, diferente dos nossos antepassados, não falamos mais de morte, conceitos para pensá-la não são formulados, mas a ela se "reage com sorrisos embaraçados, com silêncios reticentes, com desconversas que são signos do aparecimento de algo cuidadosamente reprimido" (Rodrigues, 1983, p. 188).

Silenciar é quase obrigação. Não se sabe agir diferente porque pouco se pensa sobre a morte. Quando ela ocorre, o redor pode estar desprevenido e é necessário um tempo para que se recomponha. O silenciar fornece uma ilusão confortável à comunidade e permite que as pessoas sigam agindo como se fossem felizes (Rodrigues, 1983, p. 188).

Segundo Freire (2006), da década de 1960 para cá é que a morte ganhou contornos de tabu, que não se deve falar em público nem tampouco obrigar os outros a fazê-lo e se acentuou profundamente nas últimas três décadas do século 20 com o individualismo das relações sociais (Freire, 2006, p. 14). Isto contribui para explicar a dificuldade de, agora, Joaquim verbalizar a morte da mãe, pois deixa transparecer ao longo de toda a entrevista que pouco ou nada falou sobre isto ao longo da vida. Em uma sociedade em que o individualismo orquestra as relações, o sofrimento pelo luto é introjetado de forma solitária, como Freire (2006, p. 30-31) resume:

A dor grita nos enlutados. Mas dentro deles. O social faz sua economia de gestos e sentimentos. E põe-se surdo diante do sofrimento daquele que sofre uma perda. Esta dor transforma-se em algo inaudível, e por isso mesmo indizível. Para não sofrer mais diante da inadequação de seu sofrimento num âmbito mais amplo, o enlutado cala e põe-se mudo. Existe, assim, um afastamento da dor da perda no cotidiano, e o jogo entre indivíduo e sociedade tornase quite: um não fala por não ter quem ouça e quem compreenda, e o outro não ouve para não incomodar-se e também para não envolver-se. 
A surpresa em ser solicitado a lembrar da situação da morte da mãe e de todos os contornos que ela tomou na vida dele demonstra que Joaquim também teve o silêncio como recurso. Os outros familiares, como os tios e o irmão, possivelmente também compartilharam da mesma ausência de palavras sobre o assunto e demonstração de luto aos demais. Freire (2006) lembra que o enlutado depara-se com um sentimento de inadequação social levando a uma introspecção, mágoa, inquietação, com receio de que ao demonstrar o seu pesar seja visto como uma fraqueza. Análise bastante adequada, se tomarmos como base a biografia de Joaquim. Esta discrição ao externar o sofrimento pode ser traduzida como uma espécie de vergonha por expressar as emoções. Este temor em mostrar-se abalado pela perda do ente querido parece denunciar a ideia de fracasso e medo e por isto é evitado (Koury, 2003, p. 22). O autor afirma ainda que a tônica moderna no Brasil urbano no processo de luto é uma cumplicidade na indiferença aparente pela morte, um pacto onde o indivíduo enlutado fica restrito a si mesmo (Koury, 2003, p. 34).

A leitura de que um elo intrafamiliar se quebra após a morte de um parente em comum pode ser aplicada ao caso de Joaquim e ser mais um item que dá força ao rompimento realizado por ele com relação à sua família de origem. Koury explica que os "códigos de proximidade que uniam e garantiam o sentimento de família ruem através das barreiras que vão sendo impostas pelos silêncios das mágoas e do desconforto" (2003, p. 121). Quando Joaquim se dá conta em meio à narrativa de que a tia fez o que pode por ele e ele nunca agradeceu, nunca foi muito atencioso e se manteve sempre distante, vai ao encontro do que disse Koury. Chamar o outro para conversar passa a ser uma espécie de humilhação. Ao mesmo tempo, deixar de fazer isso, gera uma culpa enorme. Somado à culpa, o medo de ser mal interpretado amplia o silêncio e a frieza das relações (Koury, 2003, p. 121-122).

\section{Estigma e rompimento identitário}

A forma como Joaquim demonstra querer ser visto pelo interlocutor, é totalmente centrada nos abrigos. O suposto luxo do novo abrigo fica em evidência para dizer que estava bem e que teve uma vida "normal". Ele introduz o relato sobre o novo abrigo dizendo que viviam como uma família "normal": os guris tinham um quarto e as gurias, outro. Cada um com sua cama e seu roupeiro com roupas da moda e entre os quartos dos meninos e das meninas tinha o da mãe social. "Muito luxo. Escreve aí que lá tinha muito luxo", disse ele reiteradas vezes. Tinha banheiro separado, sala e cozinha enormes, televisão de 42 polegadas, computador. 
Adotando uma postura defensiva, Joaquim faz questão de dizer que sempre levou uma vida "normal", possivelmente, como uma tentativa de se livrar de um estigma. Segundo Goffman, o conceito de estigma conecta-se ao de um "indivíduo que está inabilitado para a aceitação social plena" (1982, p. 7). Joaquim não quer assumir o rótulo de órfão que "não tem pai nem mãe" e que cresceu em um abrigo, pois não quer que as pessoas sintam pena dele. Enquanto o estranho está à nossa frente, podem surgir evidências de que ele tem um atributo que o torna diferente de outros que se encontram numa categoria em que pudesse ser incluído, sendo, até, de uma espécie menos desejável - num caso extremo, uma pessoa completamente má, perigosa ou fraca (Goffman, 1982, p. 12).

Ao citar repetidas vezes as expressões "normal", "éramos uma família normal no abrigo", "como todo mundo", "igual ao que tem na rua", Joaquim demonstra o seu esforço de se livrar do estigma de ter crescido sem a família, dentro do abrigo. Ou seja, o estigma teria muito mais a ver com a condição de abrigado do que com ser filho de uma mulher assassinada pelo companheiro.

Aqui está o centro do tema orfandade em um contexto de violência doméstica: ao ser encaminhado para um abrigo, aos cinco anos, tornou-se um objeto de estigma desde a infância. Mesmo explicitando ter superado o passado, pois trabalha e ganha o seu sustento, fala com os irmãos e com os tios, individual e socialmente, cria estratégias em torno deste estigma.

como a gente tem um momento que a gente tá tá muito pra baixo se não tivé uma pessoa pra ti ANIMÁ "tu já não tem pai" tu já não tem mãe tu mora sozinho minha vida tá uma Bosta, falo bem assim, é bem sincero né, daí: pô dai eu bah ai eu ó come que ta aí não to, só me dô MAL pá porque tô aqui né por $=$ esse $=$ tipo $=$ de $=$ coisa $=$ mas $=$ as =pessoa $=$ pegam já vende tudo que tem já se atira nas droga já já acaba vir- vivendo Mais um na sociedade "é isso ai que acaba sendo" mais um na sociedade que ninguém te olha mais.

Joaquim faz questão de demonstrar ser diferente dos demais, dizendo, por exemplo, que a tia colocou-nos no abrigo, mas visitava com frequência. Com exceção da tia, por quem nutre afeto e gratidão, procura manter distância dos parentes e demarca bem o sentimento de não fazer e nem querer fazer parte do universo familiar, nem social no qual a família de origem está inserida. A todo o momento, quer parecer ter conseguido fazer uma transição de patamar social, inclusive em termos de valores, e não encontra mais nada 
em comum entre ele e os parentes. Faz questão de se apresentar como diferente dos demais familiares, sendo que ele "pensa para frente" e os demais ficam na "mesmice".

A construção desta nova identidade exige muitos esforços. Joaquim demonstra saber lidar com as fronteiras existentes na sua trajetória. Nesta busca de uma nova vida, sabe que o fator bairro é importante. Por isto, ao dizer onde mora, jamais conta o nome da vila, mas usa um shopping center de classe média da cidade como ponto de referência. A argumentação de Joaquim é abordada por Lúcio Kowarick (2009) como efeito-bairro: o contexto em que o local de moradia afeta outros aspectos da vida. A área da cidade onde o sujeito reside está envolta em elementos que dizem respeito a algo muito além de um endereço ou uma noção de distância de outros pontos da cidade, carrega consigo estereótipos e pré-julgamentos enxergando a pessoa não como única, mas como um ser que faz parte de uma engrenagem em que, no imaginário do outro, só existe bandido e gente com má índole. Isto fica evidenciado na hora de conseguir empregos, arrumar namorada, fazer amigos e etc. (Kowarick, 2009).

Mas a ideia conservadora apresentada acima também está incutida no próprio morador, principalmente o jovem, que terá de cercar-se de mais valores morais para conseguir recusar trabalho no crime. É a sedução para a tal "funçãozinha", trazida por Joaquim, que expõe o jovem sempre ao limite, podendo gerar no povo a pré-concepção de que, se ele ainda não entrou para o crime, é uma questão de tempo para que ocorra. Assim, busca este afastamento das origens. As hierarquias do mundo social são demarcadas pelo espaço físico da cidade, já que as periferias são compostas pelo bairro dos pobres e eles "criam uma identidade de que só faz sentido por contraste, compartilhando esse espaço geográfico e social com seu local de moradia, em oposição ao centro" (Sarti, 2007, p. 130).

A busca por um emprego para que pudesse se sustentar sozinho também representa fator importante nesta quebra identitária. Próximo de ter de deixar o abrigo em razão de completar 18 anos consegue emprego em um restaurante, das $8 \mathrm{~h}$ às $16 \mathrm{~h}$. Com a remuneração, que complementa aos finais de semana fazendo bico em outros restaurantes e festas, conseguia arcar sozinho com os custos de morar sozinho. É pelo trabalho que consegue achar um caminho para, aos poucos, se livrar do estigma de quem "não tem pai nem mãe" e cresceu em abrigos. Faz questão de frisar o quanto recebe de salário. No início, o ordenado era de R $\$ 1$ mil, mas como ele "trabalhava bem", não demorou para receber aumentos que até o momento da entrevista somava uma quantia de $\mathrm{R} \$ 1.950,00$. A conquista do seu próprio sustento é motivo de orgulho, 
pois consegue, na prática, se diferenciar dos demais, como sempre buscou, principalmente da sua família.

Em um mundo em que ser trabalhador representa mais do que ganhar dinheiro para se sustentar, está ligado também ao oposto de ser bandido, Joaquim demonstra claramente o alívio de estar sendo remunerado e não precisar mais voltar para a casa dos parentes. Está aí mais um ponto de rompimento com a vida antiga.

Zaluar (1985, p. 121) confirma que o trabalho dá ao pobre a redenção moral e, com isto, alcança a dignidade. Além disto, segundo a mesma autora, "a identidade de trabalhador constrói-se em parte por oposição a bandidos e vagabundos que não trabalham" (Zaluar, 1985, p. 132). Mas estar na fronteira, tentando ultrapassá-la, tentando fazer diferente daqueles com quem possui laços sanguíneos, tem sempre o custo da culpa do medo de achar que tem uma marca, um estigma. Este distanciamento de um "mundo" e esforço de aproximação de um "mundo" novo pode fazer de Joaquim um forasteiro.

Conforme a definição de Schutz (2003), o forasteiro é alguém que busca ser definitivamente aceito, ou mesmo tolerado, pelo grupo ao qual se aproxima. $\mathrm{O}$ autor sustenta que a pessoa nascida e educada em um determinado grupo "aceita o esquema já elaborado previamente de uma pauta cultural recebida de seus antepassados, mestre e autoridades como um guia indiscutido e indiscutível em todos as situações que ocorrem normalmente dentro de seu mundo social" (Schutz, 2003, p. 98). Com isto, o que Schutz (2003) esclarece é que alguém como Joaquim, que rompe com seus laços de origem e vai em busca de outro "mundo" para seguir sua trajetória terá como ônus, no mínimo, este esforço de tentar se adequar a todo o momento aos hábitos e regras deste novo "universo".

\section{Considerações finais}

Na biografia analisada, para surpresa da pesquisadora, as circunstâncias da morte de Maria, mãe de Joaquim, e o cenário violento em que o entrevistado estava inserido antes do óbito dela não se apresentam como tema central da narrativa. É o estigma de ter vivido em abrigos, de ser visto pela sociedade como alguém que "não tem pai nem mãe", que norteia a vida vivenciada do biografado.

O interesse de apresentação de Joaquim durante as entrevistas esteve sempre voltado para a condição de alguém ciente de uma ideia pré-concebida por parte daqueles que o cercam: de um menino que cresceu no abrigo, que mora em uma vila, que é pobre e que não foi criado pelos pais. Os motivos que levaram a este cenário parecem ser secundários na biografia dele. Joaquim 
recusa, no sentido manifesto ${ }^{4}$ da sua narrativa, que a morte tenha ocorrido por alguma investida violenta por parte do padrasto - o que aparece apenas em seu conteúdo latente -, e se concentra nas estratégias de se livrar do estigma da orfandade. É com relação a este último tema que Joaquim busca recursos para sobreviver e ser aceito na sociedade.

A mescla entre as repercussões pessoais e sociais foi justamente o foco do nosso trabalho. Dentro do propósito da abordagem metodológica de narrativas biográficas desenvolvida por Gabriele Rosenthal, portanto, cumprimos com nossa ambição: investigar o desconhecido, apreender o sentido subjetivamente visado, reconstruir o sentido latente, reconstruir a complexidade de estruturas de ação a partir do caso particular, descrever o meio social e o agir, desenvolver teorias e hipóteses empiricamente fundadas e verificá-las a partir de um caso particular (Rosenthal, 2014b).

Mais importa a forma como o biografado introjeta tudo o que aconteceu neste contexto de violência doméstica do que os detalhes factuais da morte e outros aspectos marcantes de sua vida. É neste ponto que a diferenciação aplicada por Rosenthal entre fato e vivência aparece. Como cientistas sociais não estamos interessados na reconstituição da cena do crime ou dos dias que sucederam e antecederam a morte de Maria. Estamos, sim, em busca da reconstrução do sentido subjetivamente visado pelo biografado, a maneira como os fatos foram experienciados por ele e depois ganharam um novo significado para compor o discurso da presente narrativa. Dentro do conceito de Alfred Schutz, um passado movediço e em constante transformação.

No caso de Joaquim, a morte da mãe é tomada por uma série de incertezas, o que pode se repetir em diversas outras situações que envolvem este tipo de orfandade. Mais pesquisas precisam ser realizadas neste sentido, mas uma hipótese é a de que a mesma incerteza vivida por Joaquim possa se repetir em outros casos. Como a morte em si representa um tabu para a sociedade ocidental, a família pode ter se fechado em torno deste assunto, encerrando qualquer questionamento.

Ainda que o menino tenha presenciado as agressões de Altair, o padrasto, contra Maria, e deduzido que esta tenha sido a causa da morte da mãe, o fato de o assunto ter sido silenciado e não debatido pela família na presença de

\footnotetext{
${ }^{4}$ No momento da análise dos dados são utilizados procedimentos da teoria fundamentada (grounded theory) - empiricamente sedimentada, que estruturam o material textual em categorias gerais, conforme os critérios do pesquisador. Já no momento da reconstrução e sequencial toma-se a estrutura temporal ou forma sequencial do texto como base para a interpretação. Cada sequência é considerada em sua inserção na forma geral, tornando possível "apreender o conteúdo não apenas manifesto - como ocorre na análise do conteúdo -, mas também latente, as “entrelinhas"” (Rosenthal, 2014b, p. 25).
} 
Joaquim e seu irmão, deixa margem para a subjetividade de Joaquim criar para si um desfecho mais aprazível. Mesmo que, em diversos momentos, mencione a incerteza de que a mãe morreu no parto, que esta foi a versão que a família contou a ele e que quanto a isto não pode afirmar se foi verdade ou não. A desconfiança dos vizinhos de que Maria tenha sido assassinada por Altair também vem à tona na narrativa, mas é a versão da morte no hospital, ao dar à luz, que Joaquim sustenta com maior desenvoltura. Dito isto, é possível afirmar que uma das formas de viver a orfandade por violência doméstica seja negar ou minimizar que ela tenha existido nestas condições.

É preciso que a sociologia e outras ciências se encarreguem de investigar não só a orfandade em um contexto de violência doméstica, mas também os efeitos para a criança e o adolescente em presenciar estas agressões, que podem culminar em homicídio ou serem perpetradas ao longo da vida familiar, tendo os filhos como testemunhas constantes.

\section{Referências}

DREHER, Jochen. Alfred Schutz. In: George Ritzer; Jefrey Stepninsky (orgs.). The Wiley-Blackwell companion to major social theorists. Malden: Blackwell Publishing, v. 1, 2011, p. 489-510.

FONSECA, Claudia. Família, fofoca e honra: etnografia de relações de gênero e violência em grupos populares. Porto Alegre: Editora da Ufrgs, 2004.

FERRARA, Andrea Paula. Orfandade e estigma: vivências de jovens órfãos em decorrência da Aids. São Paulo: USP, 2009. Dissertação de mestrado em Saúde Pública.

FREIRE, Milena C. B. O som do silêncio: isolamento e sociabilidade o trabalho de luto. Natal: Editora da UFRN, 2006.

GOFFMAN, Erving. Estigma: notas sobre a manipulação da identidade deteriorada. Rio de Janeiro, Zahar, 1982.

KOURY, Mauro Guilherme Pinheiro. Sociologia da emoção: o Brasil urbano sob a ótica do luto. Petrópolis: Vozes, 2003.

KOWARICK, Lúcio. Viver em risco: sobre a vulnerabilidade socioeconômica e civil. São Paulo: Editora 34, 2009.

LEIS, Héctor Ricardo. A sociedade dos vivos. Sociologias, v. 5, n. 9, 2003. p. 340-353.

MILANI, Rute Grossi. Violência doméstica: recursos e adversidades de crianças e famílias pós-ações do Conselho Tutelar. Ribeirão Preto, Universidade de São Paulo, 2006. Tese de doutorado em Medicina, Faculdade de Medicina de Ribeirão Preto, Departamento de Neurologia, Psiquiatria e Psicologia Médica, USP.

MORATILLA-OLVERA, M. I., TARACENA-RUIZ, B. E. Vulnerabilidad social y orfandad: trayectoria vital de una adolescente. Revista latinoamericana de ciencias sociales, niñez y juventud, v. 10, n. 2, p. 841-854, 2012. 
PEREIRA, José Carlos. Procedimentos para lidar com o tabu da morte. Ciência e saúde coletiva, v. 18, n. 9, p. 2699-2709, $2013<10.1590 /$ S1413-81232013000900025>.

PINTO, Célia Regina Jardim. Uma história do feminismo no Brasil. São Paulo: Editora Fundação Perseu Abramo, 2003.

RODRIGUES, José Carlos. Tabu da morte. Rio de Janeiro: Achiamé, 1983.

ROSENTHAL, Gabriele. História de vida vivenciada e história de vida narrada: a interrelação entre experiência, recordar e narrar. Civitas. v. 14 n. 2, p. 227-249, 2014a $<10.15448 / 1984-7289.2014 .2 .17116>$.

ROSENTHAL, Gabriele. Pesquisa social interpretativa: uma introdução. Porto Alegre, Edpucrs, 2014b.

SAFFIOTI, Heleieth I. B. Já se mete a colher em briga de marido e mulher. São Paulo em perspectiva, v. 13, n. 4, p. 82-91, 1999.

SAFFIOTI, Heleieth I. B. Contribuições feministas para o estudo da violência de gênero. Cadernos Pagu, n. 16, p. 115-136, 2001.

SANTOS, Cecília Macdowell; IZUMINO, Wânia Pasinato. Violência contra as mulheres e violência de gênero: notas sobre estudos feministas no Brasil. Estudios interdisciplinarios de América Latina y el Caribe, v. 16, n. 1, p. 147-164, 2005.

SARTI, Cynthia Andersen. A família como espelho: um estudo sobre a moral dos pobres. São Paulo: Cortez, 2007.

SCHUTZ, Alfred. El forastero: ensayo de psicologia social - estudios sobre teoría social. Escritos II. Buenos Aires: Amorrortu Editores, 2003.

SCHUTZ, Alfred. Sobre fenomenologia e relações sociais. Petrópolis: Vozes, 2012.

SOUSA, Tânia Sofia. Os filhos do silêncio: crianças e jovens expostos à violência conjugal - um estudo de casos. Lisboa: Universidade Lusófona de Humanidades e Tecnologias, 2013.

WELZER-LANG, Daniel. A construção do masculino: dominação das mulheres e homofobia. Revista Estudos Feministas, v. 9, n. 2, p. 460-481, 2001.

ZALUAR, Alba. A máquina e a revolução: as organizações populares e o significado da pobreza. São Paulo: Editora Brasiliense, 1985.

Recebido em: 12 out. 2015

Aprovado em: 15 dez. 2015

Autora correspondente:

Kamila Almeida

Centro de Análises Econômicas e Sociais - Caes-Pucrs

Av. Ipiranga 6681 - Prédio 50, sala 1005

90619-900 Porto Alegre, RS, Brasil 